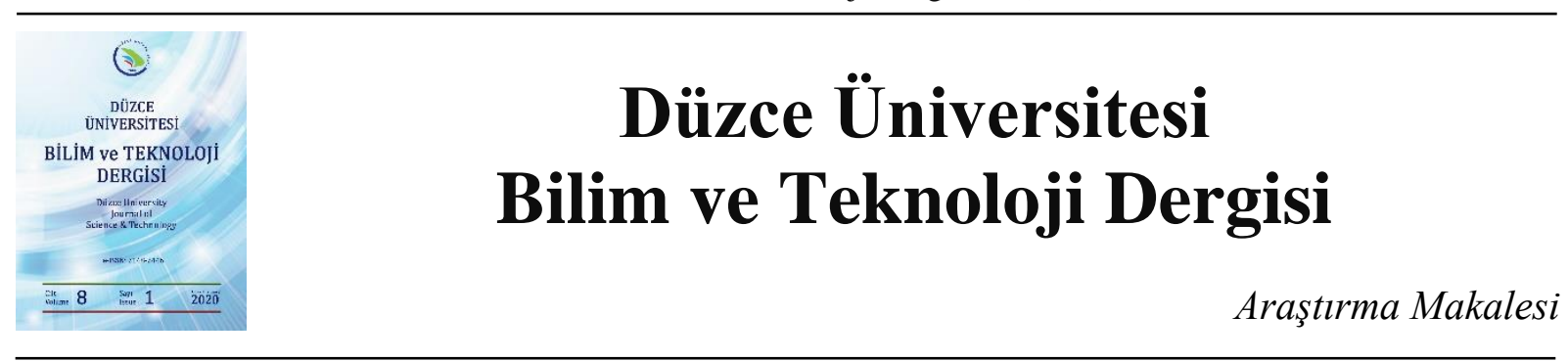

\title{
Toplu Konutlarda Reaktif Güç Kompanzasyonunun Uygulanabilirliğinin Analizi
}

\author{
Özkan SEZER ${ }^{\mathrm{a}, *}$, (D) Nihat DALDAL ${ }^{\mathrm{b}}$, (D) İbrahim YÜCEDAĞ ${ }^{\mathrm{c}}$

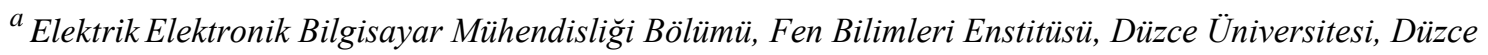 \\ TÜRKIYYE \\ ${ }^{b}$ Elektrik Elektronik Mühendisliği Bölümü, Mühendislik Fakültesi, Bolu Abant İzzet Baysal Üniversitesi, Bolu, \\ TÜRKIYE \\ ${ }^{c}$ Bilgisayar Mühendisliği Bölümü, Teknoloji Fakültesi, Düzce Üniversitesi, Düzce, TÜRKIYE \\ Sorumlu yazarın e-posta adresi ozkansezer@meb.gov.tr
}

DOI: $10.29130 /$ dubited.632630

\begin{abstract}
ÖZET
Bu çalışmada, teknolojinin hızla gelişmesi sonucu ortaya çıkan elektrik enerjisi ihtiyacının karşılanması için yapılabilecek iyileştirmeler ele alınmıștır. Bu ihtiyacın karşılanması için enerji üretiminin artııılmasının yanı sıra üretilen enerjinin verimli bir şekilde kullanılması büyük önem arz etmektedir. Enerjinin üretimi ve planlanması, enerji verimliliği açısından son derece önemlidir. Reaktif enerji tüketimini minimuma indirmek yani kompanzasyon yapmak, verimlilik artırır. Ancak günümüzde kompanzasyon sadece belirli gücün üstündeki işletmelerde uygulanmaktadır. Günümüzde elektrik üretimi zor ve pahalı hâle gelmiştir. Bu konuda yapılacak her türlü tasarruf ve iyileştirme; ülke ekonomisine ve enerji verimliliğine büyük katkı sağlayacaktır. Bu çalışmada, meskenlerde (kompanzasyonun zorunlu kabul edilmediği mekânlarda) kullanılan elektriğin kompanzasyona ihtiyaç duyulup duyulmadığı incelenmiştir. Yapılan bu çalışmada, dört kişilik bir ailenin kaldığı meskene, enerji analizör sistemi kurularak evin elektrik tüketimi iki aylık süreyle izlenmiş ve elde edilen verilere göre değerlendirmeler yapılmıştır.
\end{abstract}

Anahtar kelimeler: Güç faktörü, Kompanzasyon, Enerji verimliliği, Reaktif enerji

\section{Analysis of the Applicability of Reactive Power Compensation in Mass Housing}

\begin{abstract}
In this study, the improvements that can be made to meet the electrical energy demand arising from the rapid development of technology are discussed. In order to meet this need, besides increasing energy production, it is very important to use the energy produced efficiently. The generation and planning of energy is extremely important in terms of energy efficiency. Minimizing reactive energy consumption, ie compensating, increases efficiency. However, nowadays, compensation is applied only in enterprises above certain power. Today, electricity generation has become difficult and expensive. All kinds of savings and improvements to be made in this regard; will make a major contribution to the national economy and energy efficiency. In this study, it is investigated whether the electricity used in residential areas (in places where compensation is not accepted as compulsory) is needed. In this study, the electricity consumption of the house was monitored for two months by using an energy analyzer system and evaluations were made according to the data obtained.
\end{abstract}

Key words: Power factor, Compensation, Energy efficiency, Reactive energy

Geliş: 13/10/2019, Düzeltme: 02/01/2020, Kabul: 06/01/2020 


\section{GIRIS}

Üretim çeşitliliğinin ve yenilenebilir kaynakların sınırlı olması, mevcut kaynakların gün geçtikçe tükenmesi ve ihtiyaç duyulan miktarın giderek artmasıyla elektrik enerjisi, stratejik bir hâl almaktadır. Son kırk yılda enerji üretimi 4 kat artmasına karşın elektrik tüketimi 10 kat artmışıır [1]. Bu nedenle dünyada ve ülkemizde enerji verimliliği ve tasarruf programları uygulanmaktadır. Son yıllarda, sanayileşmenin ve bireysel elektrikli cihaz kullanımının artmasıyla birlikte endüstride ve meskenlerde kullanılan endüktif güç tüketiminde büyük artış olmuştur [2]. Endüktif yükler, şebekeden iş yapan aktif gücün yanında reaktif güç de çeker [3].

İletim hattını yüklemesine rağmen, bu güç bileşeni işe dönüştürülmez [4]. Bu nedenle, güç sistemlerinde çekilen reaktif güç nedeniyle meydana gelen kayıpların mümkün olduğunca küçük tutulmasına hatta sıfırlanmasına çalışılmalıdır [5]. Şebeke kayıplarındaki azalma, üretim maliyetinin azalmasını, enerji sisteminin ekonomik ve verimli olmasını sağlayacaktır [6]. Bunu yapmanın tek yolu ise iletim hattının beslediği endüktif yüklerin ihtiyacı olan reaktif enerjiyi, yükün bulunduğu en yakın yerde kompanze etmektir [7-10]. Bu çalışmamızda tüketilen reaktif güç ve reaktif gücün toplam tüketimdeki payı ortaya konmuştur [11-12]. Deneysel çalışmayla beraber, reaktif tüketim gözlenerek mesken ve ticari işletmelerde kompanzasyon zorunluluğunun gerekliliği analiz edilmişstir.

\section{II.REAKTIF ENERJİ VE CEȘITLERİ}

Alternatif akımda yükler ve enerji; rezistif (omik) yükler (aktif güç), endüktif yükler (reaktif güç), kapasitif yükler (reaktif güç) olmak üzere üç çeşittir.

Bu yüklerin akım ve gerilim vektör diyagramları da Şekil 1'deki gibi olacaktır.

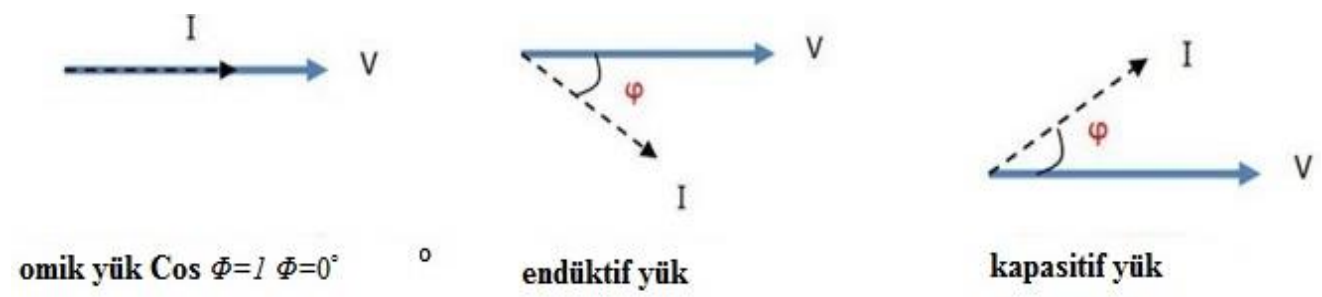

Şekil 1. Yüklerin akım gerilim vektör diyagramları

Omik yükte akım ve gerilim arasında herhangi bir açısal fark yoktur. Ancak endüktif yükte akım gerilimden geride, kapasitif yükte ise akım gerilimden ileride olmaktadır. Enerji ise reaktif güç (Q), aktif güç (P) ve görünür güç $(\mathrm{S})$ olmak üzere üç çeşittir [13].

Görünür güç $S^{2}=P^{2}+Q^{2}, S=\sqrt{P^{2}+Q^{2}}$

Aktif güç $\quad P^{2}=S^{2}-Q^{2}, P=\sqrt{S^{2}-Q^{2}}$

Reaktif güç $Q^{2}=S^{2}-P^{2}, Q=\sqrt{S^{2}-P^{2}}$

\section{A. REAKTIF GÜÇ}

Reaktif güç; endüktif yüklü devrelerde, manyetik devrenin uyartımı için çekilip bir sonraki periyotta iade edilen güçtür. Reaktif güç "Q" harfi ile gösterilir. Bu güç, endüktif yük üzerinde harcanmaz. Sadece depo edilir ve tekrar kaynağa gönderilir. Dolayısıyla kaynakla endüktif yük arasında sürekli olarak 
reaktif güç alışverişi yapılır. Son kullanıcı ve sanayi bazında talep arttıkça reaktif yükler de çok hızlı bir şekilde artmaya başlar. Bu yüklerin büyük çoğunluğu omik-endüktif özelliktedir [13].

\section{III.KOMPANZASYON}

Kompanzasyon; elektrik tüketiminin reaktif olduğu alanlarda, uygun kompanzasyon yöntemleriyle endüktif veya kapasitif yüklerin etkisini idealde sıfırlamaktır. Reaktif enerjinin kompanze edilmesi; şebeke taşıma kapasitesini arttırma ve enerji israfını önleme açısından ülke ekonomisi için vazgeçilmezdir. Enerji Piyasası Düzenleme Kurumunun 08/01/2004 tarih ve 284/2 sayılı Karar'ıyla reaktif enerjinin kompanze edilmesi zorunlu tutulmuştur. (Bu kurul kararı 15/01/2004 tarih ve 25347 sayılı Resmi Gazete'de yayımlanarak yürürlüğe girmiştir.)

Bu Karar'a göre konut, villa, mesken aboneliklerinde standart sayaç takılıp reaktif ve kapasitif sayaç kullanılmadığ 1 için herhangi bir ceza uygulanmaz.

Aynı Karar'a göre işletmelerde sözleşme gücü $9 \mathrm{~kW}$ üzeri için reaktif ve kapasitif ölçen kombi elektrik sayacı kullanımı zorunludur. Bu tür sayaç takılmadığı durumda, tüketicinin $\% 90$ reaktif enerji kullandığı varsayılarak elektrik fatura bedeline bu miktar ilave edilir. İlgili Karar, işletmelerde sözleşme gücü 9 kW üzeri için kompanzasyon sistemini zorunlu tutar. İşletmelerde sözleşme gücü $9 \mathrm{~kW}-29,9 \mathrm{~kW}$ arası \%33 reaktif sınır, \%20 kapasitif sınırı aştığı zaman ceza uygulanmaktadır. İşletmelerde sözleşme gücü $30 \mathrm{~kW}$ üstü \%20 reaktif sınır, \%15 kapasitif sınırı aştığı zaman ceza uygulanmaktadır [14].

T.C. Enerji Piyasası Düzenleme Kurumunun Ocak/2017 tarihli Elektrik Piyasası Sektör Raporuna göre elektrik tüketiminin tüketici türündeki dağılımı aşağıdaki Tablo 1'de görüldüğü şekildedir [15].

Tablo 1. Elektrik tüketiminin tüketici türündeki dağılımı

\begin{tabular}{lcc}
\hline Tüketici türü & Tüketim miktarı $(\boldsymbol{M W h})$ & Oran $(\boldsymbol{\%})$ \\
\hline Aydınlatma & $430.893,15$ & 2,259 \\
\hline Mesken & $5.345 .823,36$ & 28,023 \\
\hline Sanayi & $7.474 .233,09$ & 39,180 \\
\hline Tarımsal sulama & $84.486,48$ & 0,443 \\
\hline Ticarethane & $5.741 .074,89$ & 30,095 \\
\hline Genel Toplam & $\mathbf{1 9 . 0 7 6 . 5 1 0 , 9 8}$ & $\mathbf{1 0 0}$ \\
\hline
\end{tabular}

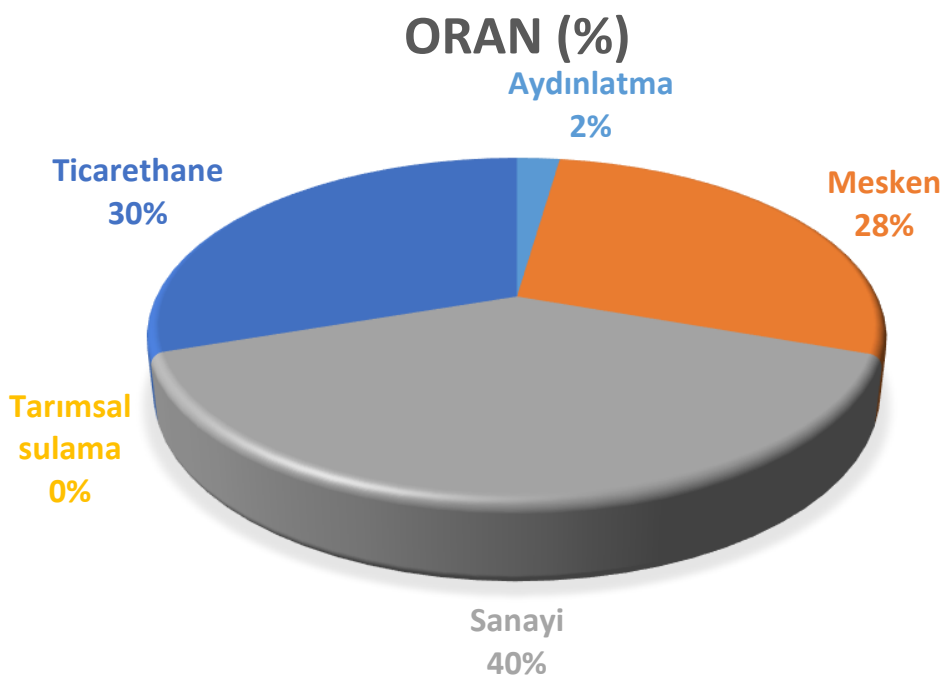

Şekil 2. Elektrik tüketiminin tüketici türündeki dăğlımı 
Şekil 2'de görüleceği üzere enerjinin 1/3'ü meskenlerde ve yine 1/3'ü ticarethanelerde tüketilmektedir. $\mathrm{Bu}$ yüksek orana rağmen kompanzasyon bu yerlerde zorunlu değildir. Ancak belirtilen oranlar bu mekânlarda da kompanzasyon uygulamasının zorunlu hâle getirilmesini gerekli kılmaktadır.

\section{IV.DENEYSEL CALIȘMALAR}

Tasarlanan deney düzeneğinde enerji analizörü, her faz için akım trafosu, her faz için sigorta, klamens, yeteri miktarda montaj kablosu ve uygun pano kullanılmıştır. Devrede, en önemli kısım olan enerji analizörü; faz-nötr gerilimleri (L1-L2-L3), faz-nötr akımları (L1-L2-L3), aktif güçler (L1-L2-L3), reaktif güçler (L1-L2-L3), $\cos \Phi$ (L1-L2-L3), $\tan \Phi$ (L1-L2-L3), gerilim-akım-frekans ortalamalar1 (L1L2-L3), toplam enerjiler (L1-L2-L3) ve benzeri hat parametrelerini ölçüp kaydeden ve rs-485 (modbus) haberleşme arabirimi sayesinde dış ortama tüm değerlerin anlık olarak iletimini sağlayan mikroişlemcili bir yapıya sahiptir. Kullanılan akım trafoları ise enerji analizörünün direkt olarak ölçemeyeceği akım değerleri için ev kullanımına uygun akım oranlarında akım trafosu (25/5) seçilmiştir. Ayrıca bilgisayar bağlantısı için uygun bir usb-485 çevirici kullanılmıştır.

Meskenlerde kompanzasyonun gerekliliğini sorgulamak için Şekil 3'te görülen enerji analizörlü bir sistem tasarlanmıştır. Bir enerji analizör, akım trafosu ve uygun montaj elemanlarıyla evin ana hat sigorta panosu ile elektrik hattı arasına bağlanmıştır.

Tasarlanan bu sistemle iki ay boyunca elektrik tüketimi, cosinus $\varnothing$ değerleri ve aktif, endüktif, kapasitif güç tüketimleri izlenmiş ve kaydedilmiştir.

Ayrıca Şekil 4'te verilen enerji analizörünün mod-bus çıkışı sayesinde bilgisayara bağlantı yaparak değerlerin tümünün izlenmesi ve kaydedilmesi sağlanmıştır. Ayrıca Şekil 4’te görüleceği üzere, analizörün ön panelinden istenilen anlık değerler takip edilmiştir.

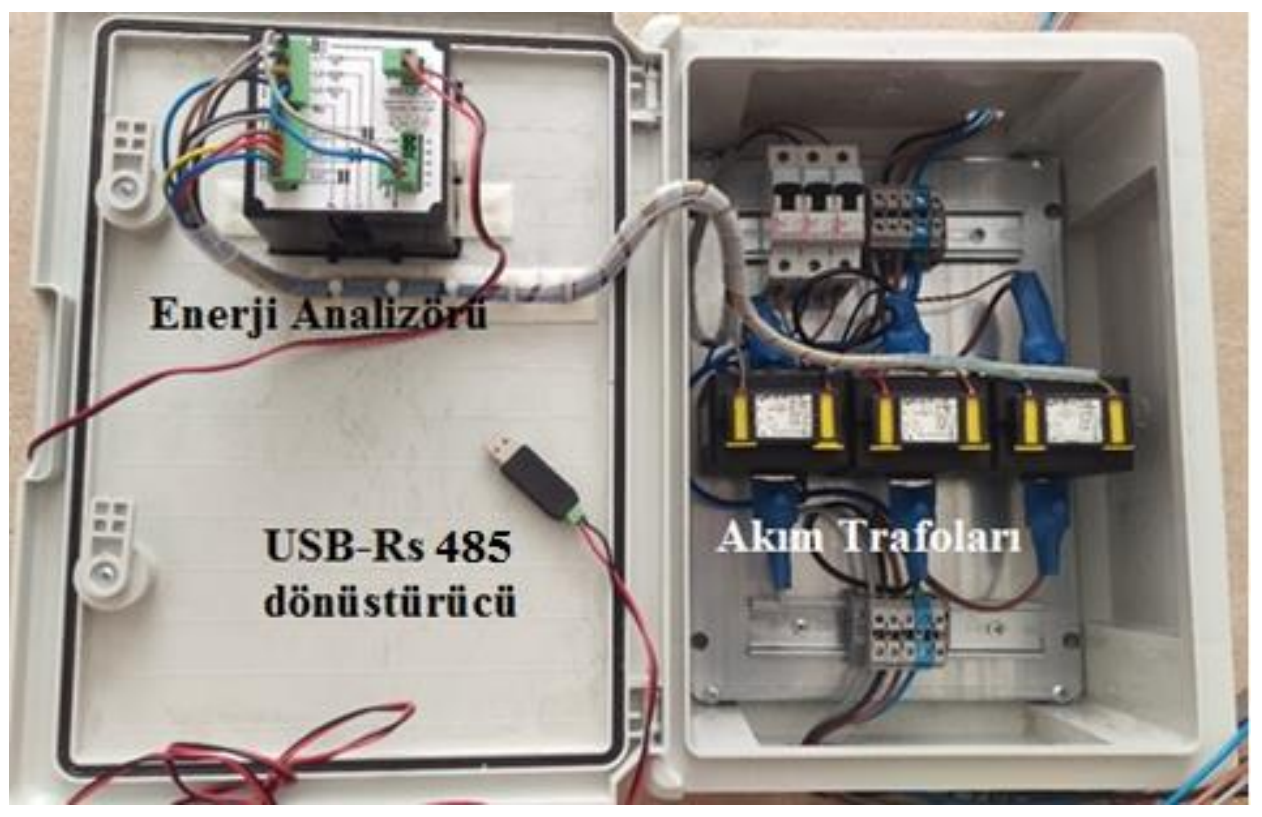

Şekil 3. Tasarlanan enerji analizör panosu 


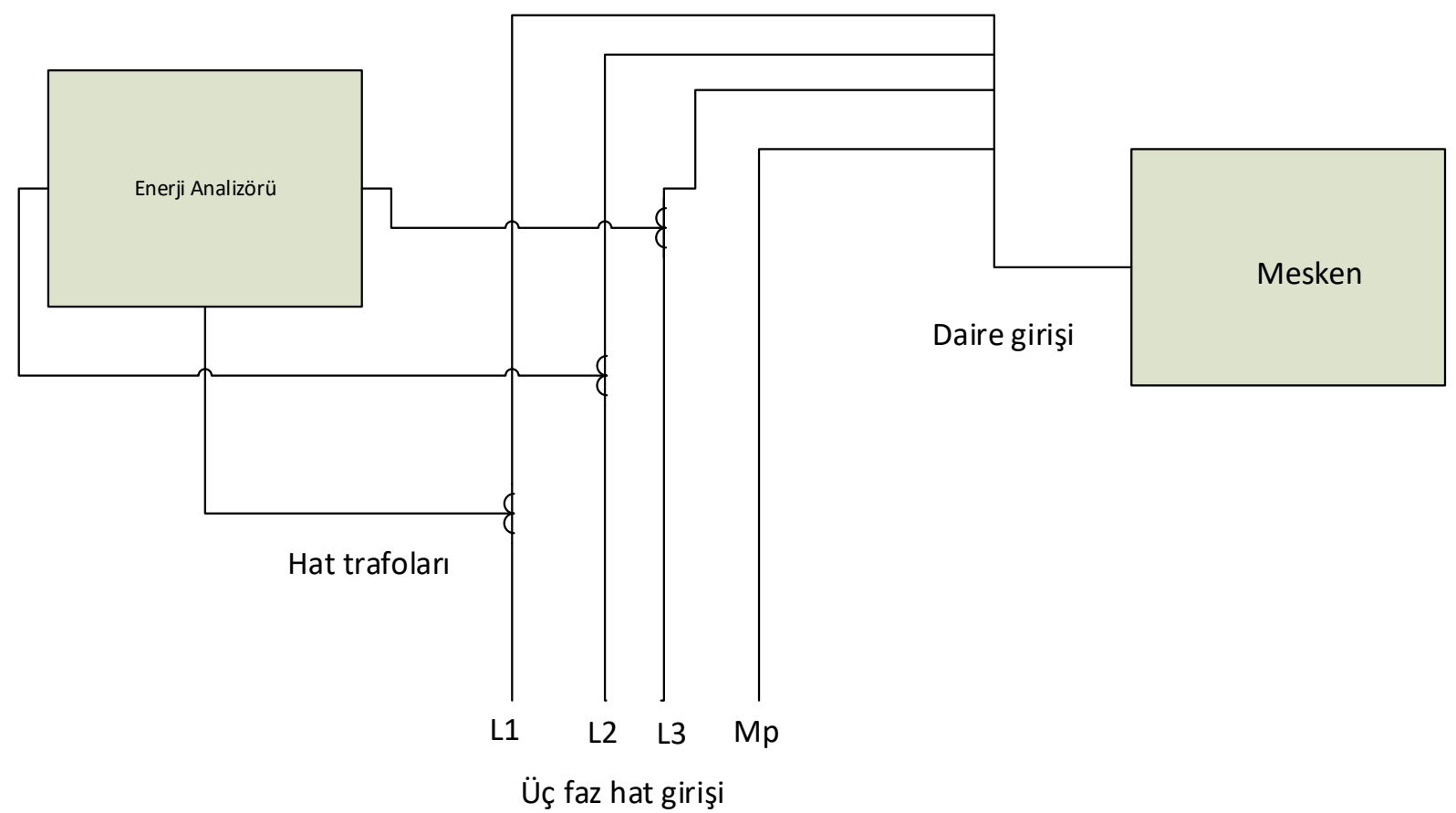

Şekil 4. Enerji analizörün bağlantı şeması, Rs-485 (mod-bus) bağlantısı ve ön paneli [Connection diagram of the power analyzer, $R S-485$ (mode-bus) connection and front panel]

Anlık değerler Şekil 5'te görüldüğü gibi eş zamanlı izlenebilmekte aynı zamanda Tablo 2'de olduğu gibi değerler Excel çıktısı olarak dış ortama aktarılabilmektedir. Burada verilerin ortalama, maksimum ve minimum değerleri tespit edilmiştir.

\begin{tabular}{|c|c|c|c|c|c|c|c|c|}
\hline \multicolumn{9}{|c|}{$\begin{array}{l}T x=0: \text { Err }=0: I D=1: F=04: S R=1000 \mathrm{~ms} \\
\text { No connection }\end{array}$} \\
\hline & Alias & 01000 & Alias & 01010 & Alias & 01020 & Alias & 01030 \\
\hline 0 & 1.FAZ-NÖTR GERILIMI & 2314 & 2.FAZ GÖRÜNÜR GÜÇ & 6 & 1.FAZ PF & 217 & 3.FAZ $\operatorname{COS} \mathrm{Fi}$ & -900 \\
\hline 1 & 1.FAZ-NÖTR AKIMI & 799 & 2.FAZ FREKANS & 5000 & 1.FAZ THD & 477 & 3.FAZ TAN Fi & -484 \\
\hline 2 & 1.FAZ AKTIF GÜÇ & 38 & 3.FAZ-NÖTR GERILIM & 2316 & 1.FAZ THID & 477 & 3.FAZ PF & -547 \\
\hline 3 & 1.FAZ REAKTIF GÜÇ & 153 & 3.FAZ NÖTR AKIM & 91 & 1.FAZ THVD & 0 & 3.FAZ THD & 1303 \\
\hline 4 & 1.FAZ GÖRÜNÜR GÜÇ & 175 & 3.FAZ AKTIF GÜÇ & 12 & 2.FAZ COS Fi & -881 & 3.FAZ THID & 1303 \\
\hline 5 & 1.FAZ FREKANS & 5000 & 3.FAZ REAKTIF GÜÇ & -5 & 2.FAZ TAN Fi & -536 & 3.FAZ THVD & 0 \\
\hline 6 & 2.FAZ-NÖTR GERILIM & 2281 & 3.FAZ GÖRÜNÜR GÜÇ & 21 & 2.FAZ PF & -611 & L1-L2 FAZ ARASI GERILIM & 3979 \\
\hline 7 & 2.FAZ-NÖTR AKIM & 27 & 3.FAZ FREKANS & 5000 & 2.FAZ THD & 1036 & L2-L3 FAZ ARASI GERILIM & 3981 \\
\hline 8 & 2.FAZ AKTIF GÜÇ & 4 & 1. FAZ $\cos \mathrm{Fi}$ & 240 & 2.FAZ THID & 1036 & L3-L1 FAZ ARASI GERILIM & 4009 \\
\hline 9 & 2.FAZ REAKTIF GÜÇ & -1 & 1.FAZ TAN Fi & 4026 & 2.FAZ THVD & d & TOPLAM AKTIF GÜÇ & 54 \\
\hline
\end{tabular}

Şekil 5. Enerji analizör çıkış değerleri

Tablo 2. Birinci faza ait akım gerilim ve güç değerleri

\begin{tabular}{|c|c|c|c|c|c|c|}
\hline \multicolumn{7}{|l|}{ modbus } \\
\hline \multicolumn{7}{|c|}{ Poll definition: ID $=1$, Function $=04$, Address $=1000$, ScanRate $=1000$} \\
\hline & $\begin{array}{c}\text { 1.faz- } \\
\text { nötr } \\
\text { gerilimi }\end{array}$ & $\begin{array}{c}\text { 1.faz- } \\
\text { nötr } \\
\text { akımı }\end{array}$ & $\begin{array}{c}\text { 1.faz } \\
\text { aktif } \\
\text { güc }\end{array}$ & $\begin{array}{c}\text { 1.faz } \\
\text { reaktif } \\
\text { güc }\end{array}$ & $\begin{array}{c}\text { 1.faz } \\
\text { görünür } \\
\text { güc }\end{array}$ & $\begin{array}{l}\text { 1.faz } \\
\text { frekans }\end{array}$ \\
\hline 2017-12-10 17:06:02.110 & 233,6 & 0,039 & 18 & 86 & 74 & 50,00 \\
\hline 2017-12-10 17:06:03.110 & 233,6 & 0,039 & 63 & 194 & 256 & 50,00 \\
\hline 2017-12-10 17:06:04.111 & 233,6 & 0,039 & 42 & 129 & 157 & 50,00 \\
\hline 2017-12-10 17:06:05.109 & 233,6 & 0,039 & 50 & 152 & 188 & 50,00 \\
\hline 2017-12-10 17:06:06.099 & 233,6 & 0,039 & 46 & 139 & 171 & 50,00 \\
\hline
\end{tabular}


Tablo 3. Senelik tüketim ve fatura raporu

\begin{tabular}{ccccccc}
\hline $\begin{array}{c}\text { Fatura } \\
\text { Tarihi }\end{array}$ & $\begin{array}{c}\text { Fatura } \\
\text { Numarası }\end{array}$ & $\begin{array}{c}\text { Fatura Tutarı } \\
(\boldsymbol{T L})\end{array}$ & $\begin{array}{c}\text { Toplam Tüketim } \\
(\boldsymbol{k} \boldsymbol{W h})\end{array}$ & $\begin{array}{c}\text { Gündüz } \\
(\boldsymbol{k} \boldsymbol{W h})\end{array}$ & $\begin{array}{c}\text { Puant } \\
(\boldsymbol{k} \boldsymbol{W h})\end{array}$ & $\begin{array}{c}\text { Gece } \\
(\boldsymbol{k} \boldsymbol{W h})\end{array}$ \\
\hline Şubat & C854080 & 64,5 & 156,54 & 75,72 & 46,98 & 33,84 \\
\hline Mart & F140223 & 60,9 & 147,879 & 73,001 & 42,058 & 32,82 \\
\hline Nisan & H819335 & 60,3 & 146,424 & 73,09 & 43,072 & 30,262 \\
\hline May1s & K151326 & 46,5 & 112,886 & 53,836 & 35,421 & 23,629 \\
\hline Haziran & M523631 & 42,6 & 103,483 & 42,167 & 36,657 & 24,659 \\
\hline Temmuz & P148250 & 45,8 & 111,085 & 52,385 & 28,557 & 30,143 \\
\hline Ağustos & 700135136 & 49,4 & 120,066 & 58,663 & 30,963 & 30,44 \\
\hline Eylül & 700529758 & 57,9 & 140,589 & 61,81 & 40,354 & 38,425 \\
\hline Ekim & 700763544 & 37,5 & 91,027 & 42,613 & 26,136 & 22,278 \\
\hline Kasim & 701015813 & 53,7 & 130,46 & 63,8 & 39,405 & 27,255 \\
\hline Aralık & 701275315 & 50,9 & 123,648 & 56,188 & 45,112 & 22,348 \\
\hline
\end{tabular}

Tablo 3'te görüldüğü üzere, çıkan değerler ele alındığında birinci faza bağlı çamaşır makinasının 130 dakika çalışması sırasında ortalama cos $\varnothing$ değerinin 0,464 olduğu ve bu değerin 0.236 ila 0.99 arasında değiştiği gözlemlenmiştir. Ayrıca fazlarda bağlı olan elektrikli cihazların tekil olarak elektrik tüketimleri ve cos $\varnothing$ değerleri gözlemlenmiştir. Endüktif güç çeken tüm cihazların (buzdolabı, bulaşık makinası, elektrik süpürgesi ve şofben) tekil olarak enerji tüketimleri ve güç katsayıları takip edilmiştir.

Tablo 4'te görüldüğü üzere, özellikle buzdolabının çalışması esnasında herhangi bir şekilde cos $\varnothing$ değerinin 0,99 değerinden sapmadığı belirlenmiştir. A+ enerji özellikli buzdolabının hem güç faktörü hem de enerji tüketimi olarak tasarruflu bir cihaz olduğu saptanmıştır. Bu durum Şekil 5'te görüleceği üzere 2017 Nisan ayından itibaren elektrik faturasındaki bariz farktan da anlaşılmaktadır [16].

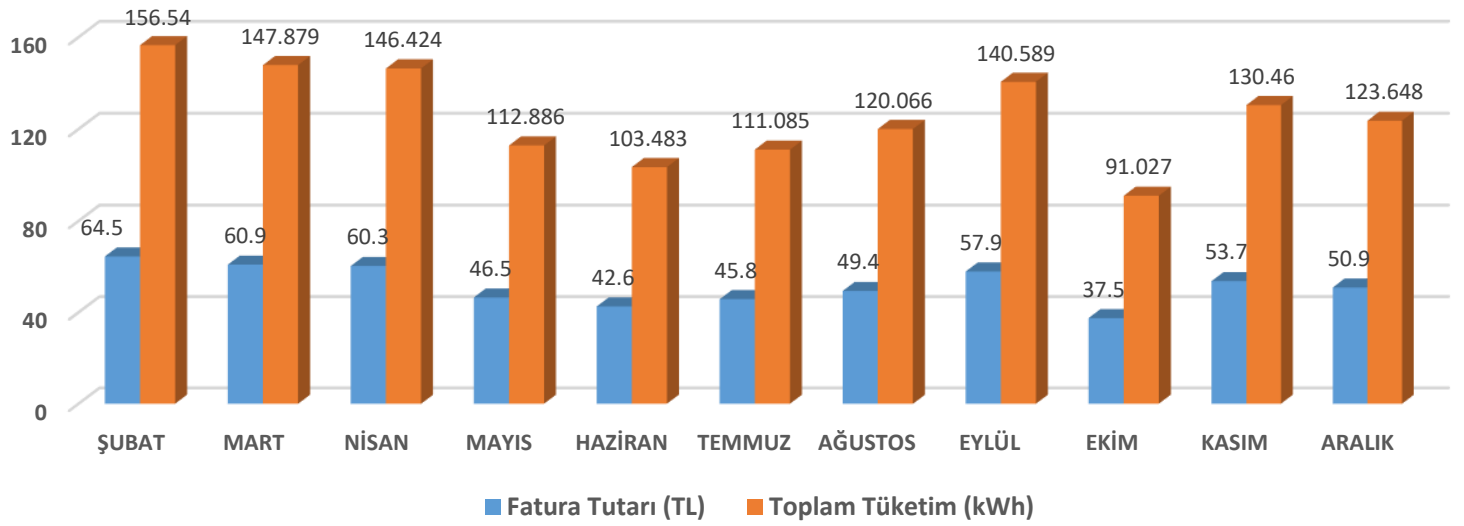

NOT: Eylül ayındaki artış faturanın 1,5 aylık olmasından kaynaklanmaktadır.

Şekil 6. Senelik tüketim ve fatura raporu grafiği

2 haftalık toplam enerji tüketimine bakıldığında ise aktif enerji: 34,817 Watt, endüktif enerji: 6380 Var, kapasitif enerji: 3026 Var'dır.

Buradan anlaşılacağı üzere reaktif güç, aktif gücün yaklaşık \%10'una karş1lık gelmektedir. Bu örneği aylık tüketime oranlarsak (aylık ortalama fatura tutarı $51.5 \mathrm{tl}$, reaktif güç toplam gücün $\% 10$ ’u olduğundan) bir dairenin aylık reaktif güç harcaması yaklaşık 5 tl olmaktadır. Meskenlerde harcanan reaktif gücün herhangi bir şekilde cezai müeyyidesi yoktur. Buna rağmen harcanan reaktif güç, hattın yüklenmesine ve ödenen aktif gücün artmasına sebep olmaktadır. Burada yapılan deney, sadece ortalama bir mesken için söz konusudur. Bu değerler; tüm konut sahipleri (sitedeki toplam daire sayısı 510 olduğundan $5 \cdot 510=2550$, y1llık $12 \cdot 2550=30600$ TL'lik reaktif güç harcamas1 söz konusudur) ve tüketimi 9kW'den aşağı olan işyerleri için hesaplandığında (tüketicilerin yaklaşık \%60'1) önemli bir yük 
oluşturmaktadır. Burada yapılacak \%20'lik güç düzeltimi 2.121.662 MWh'lik enerjiye tekabül edecektir [17]. Tablo 5 ve Şekil 6'dan görüleceği üzere bu miktar, toplam üretimin \%10'luk kısmına veya diğer bir deyişle akarsudan ve rüzgârdan elde edilen enerjiye denktir.

Tablo 4. Ocak 2017 döneminde lisanslı elektrik üretiminin kaynak bazında dağılımı ve 2016 yılı ocak ayı değeriyle karşılaştırılması (MWh)

\begin{tabular}{|c|c|c|c|c|c|}
\hline \multirow[t]{2}{*}{ Kaynak Türü } & \multicolumn{2}{|l|}{2016 Ocak } & \multicolumn{2}{|l|}{2017 Ocak } & \multirow{2}{*}{$\begin{array}{l}\text { Değişim } \\
(\%)\end{array}$} \\
\hline & Üretim $(m w h)$ & Oran (\%) & Üretim $(m w h)$ & Oran (\%) & \\
\hline Doğal gaz & $7.741 .434,47$ & 33,13 & $7.393 .426,36$ & 29,2 & $-4,50$ \\
\hline İthal kömür & $3.748 .368,66$ & 16,04 & $4.913 .045,88$ & 19,41 & 31,07 \\
\hline Barajlı hidrolik & $4.274 .930,45$ & 18,30 & $4.677 .922,23$ & 18,48 & 9,43 \\
\hline Linyit & $3.411 .545,87$ & 14,60 & $3.652 .687,92$ & 14,43 & 7,07 \\
\hline Rüzgâr & $1.267 .340,28$ & 5,42 & $1.648 .589,392$ & 6,51 & 30,08 \\
\hline Akarsu & $1.266 .998,99$ & 5,42 & $1.010 .616,94$ & 3,99 & $-20,24$ \\
\hline Motorin & $425.432,76$ & 1,82 & $706.201,90$ & 2,79 & 66,00 \\
\hline Jeotermal & $396.800,41$ & 1,70 & $505.487,01$ & 2 & 27,39 \\
\hline Taş kömürü & $290.557,56$ & 1,24 & 305142,961 & 1,21 & 5,02 \\
\hline Asfaltit & $271.544,26$ & 1,16 & $207.419,52$ & 0,82 & $-23,61$ \\
\hline Biyokütle & $155.362,50$ & 0,66 & $206.173,34$ & 0,81 & 32,70 \\
\hline Fuel oil & $109.803,45$ & 0,47 & $88.721,46$ & 0,35 & $-19,20$ \\
\hline Lng & $6.404,26$ & 0,03 & 0,00 & 0,00 & $-100,00$ \\
\hline Güneş & 0,00 & 0,00 & $1.276,26$ & 0,01 & - \\
\hline
\end{tabular}

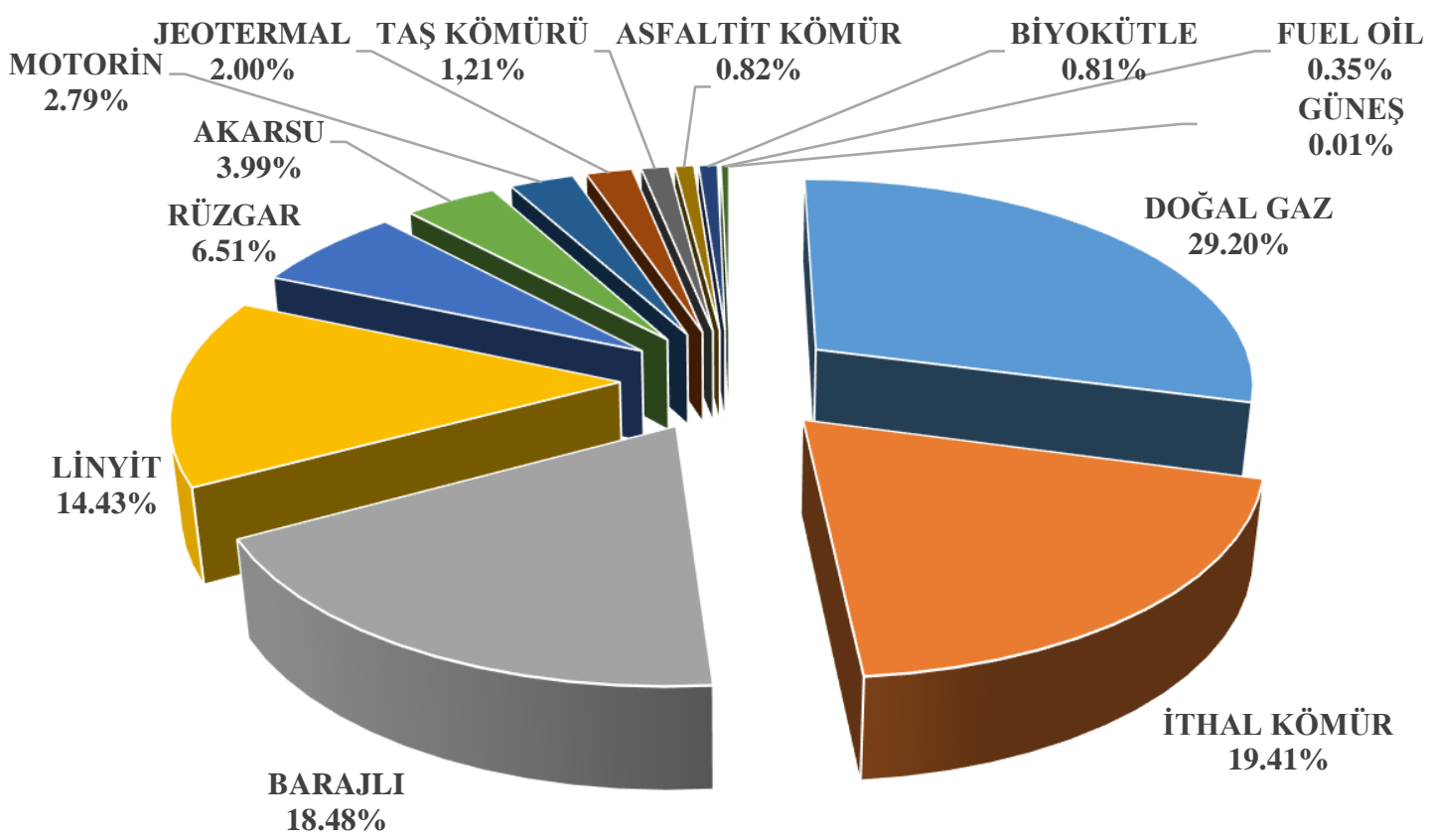

Şekil 7. Ocak 2017 döneminde lisanslı elektrik üretiminin kaynak bazında dă̆llım oranları (\%) 


\section{SONUC}

Meskenlerde tüketilen enerjide sadece aktif enerji dikkate alınmakta; endüktif ve kapasitif tüketilen enerji dikkate alınmamakta yani faturalandırılmamaktadır. Tekil olarak ele alındığında büyük bir oran teşkil etmese de toplam tüketimin \%60'ına tekabül eden enerji miktarında, ortalama \%20'lik tasarruf, göz ardı edilemeyecek bir orandır. Özellikle elektrik enerjisi üretimi esnasında, enerji ihtiyacının \%15'ini linyit, \%20'sini ithal kömür ve \%30'unu doğalgazdan karşıladığımızı düşündügüumüzde kompanzasyonun önemi daha da artmaktadır.

Her mesken veya işletme için kompanzasyon uygulaması yerine blok, site veya belirli bir bölgenin trafo merkezi bazında kompanzasyon yapılabilir. Özellikle kamu kurumları ve üniversitelerde; enerji izleme sistemleriyle kullanılan elektrĭgin kalitesi, harmonikler, yük durumları, kullanılan kompanzasyon sistemlerinin verimliliği gözlenebilir ve kullanılan cihazların bakım onarımı yapılabilir. Böylece ciddi oranda tasarruf sağlanabilir [18]. Meskenlerde ise A+ ve üstü cihazlar tercih edilerek hem tasarruf edilebilir hem de bu cihazların kendi kompanzasyon sistemleri zorunlu hâle getirilerek kayıp enerjinin önüne geçilebilir.

\section{KAYNAKLAR}

[2] S. F. Mekhamer, M. E. El-Hawary, M. M. Mansour, M. A. Moustafa, S. A. Soliman, "State of The Art in Optimal Capacitor Allocation for Reactive Power Compensation in Distribution Feeders," IEEE Large Engineering Systems Conference on Power Engineering, s. 2, ss. 61-75, 2002.

[3] R. Bayindir, Ş. Sağıroğlu, İ. Çolak, "Yapay Sinir Ağlari Tabanli Reaktif Güç Kompanzasyonu," Politeknik Dergisi, c. 10, s. 2, ss. 129-135, 2007.

[4] M. B. Latran, A. Teke, "Güç Kalitesi Problemlerini Düzelten Dağıtım Sistemine Paralel Bağlı Evirici Tabanlı Kompanzatörlerin İncelenmesi," Gazi Üniv. Müh. Mim. Fak. Dergisi, c. 29, s. 4, ss. 793 805, 2014.

[5] R. Çöteli, E. Deniz, B. Dandil, S. Tuncer, "Üç-Fazlı Üç-Seviyeli Kaskat Evirici Tabanlı, dstatcom Kullanılarak Yük Kompanzasyonu,” Politeknik Dergisi, c. 13 s. 1 ss. 7-13, 2010.

[6] R. Bayindir, Ş. Demirbaş, Ö. Sesveren, "Reaktif Güç Kompanzasyonu için Zeki Bir Simülatör Tasarımı ve Gerçekleştirilmesi," Gazi Üniv. Müh. Mim. Fak. Dergisi, c. 23, s. 3, ss. 681-688, 2008.

[7] T. Vardar, E. Çam, E. Yalçın, "Reaktif Güç Kompanzasyonu ile Enerji Verimliliği ve Kamu Kurumlarında Reaktif Güç Kompanzasyonu," International Journal of Engineering Research and Development, c. 2, s. 2, 2010.

[8] R. Bayindir, O. Kaplan, "Pic Denetimli Reaktif Güç Rölesi Tasarımı,” Gazi Üniv. Müh. Mim. Fak. Dergisi, c. 22, s. 1, ss. 47-56, 2007.

[9] M.T.L. Gayatri, M. Parimi, A.V. Pavan, "A Review of Reactive Power Compensation Techniques in Microgrids," Renewable and Sustainable Energy Reviews, vol. 81, pp.1030-1036, 2018.

[10] X. Zhou, Y. Ma, Z. Gao, S. Zhang, "Reactive Power Compensation in Motor," Proceeding of 2017 IEEE International Conference on Mechatronics and Automation, 2017. 
[11] M. B. Latran, A. Teke, "Güç Kalitesi Problemlerini Düzelten Dağıtım Sistemine Paralel Bağlı Evirici Tabanlı Kompanzatörlerin İncelenmesi," Gazi Üniv. Müh. Mim. Fak. Dergisi, c. 29, s. 4, ss. 793 805, 2014.

[12] M. M. Ertay, M. Dijle, İ. Yücedağ, "Dinamik Kompanzasyon Cihazlarında Kullanılan Evirici Yapıları: statcom ve dstatcom Topolojileri," SAÜ Fen Bil. Dergisi, c. 20, s. 2, ss. 265-279, 2016.

[13] A. Bekir, Yıldız Elektrik Devreleri II Teori ve Çözümlü Örnekler, Ders Notu, Kocaeli Üniversitesi, 2015.

[14] Anonim. (2019, 27 Kasım). TEDAŞ Reaktif Güç Kompanzasyon Ceza Oranları 2017. [Çevrimiçi]. Erişim: http://bogazicienerji.com/Teda\%C5\%9F-Reaktif-G\%C3\%BC\%C3\%A7Kompanzasyon-Ceza-Oranlar\%C4\%B1.html.

[15] "Elektrik Piyasası Sektör Raporu,” T.C Enerji Piyasası Düzenleme Kurumu, Türkiye, 2017, ss. 28.

[16] “Tüketim ve Fatura Raporu”, Enerjisa, Türkiye.

[17] “Elektrik Piyasası Sektör Raporu,” T.C Enerji Piyasası Düzenleme Kurumu, Türkiye, 2017, ss. 12.

[18] Anonim. (2019, 27 Kasım). Bir Üniversite Yerleşkesi Enerji İzleme Örneği 2017. [Çevrimiçi]. Erişim: http://entes.com.tr/bir-niversite-yerleskesi-enerji-izleme-ornegi.asp, http://entes.com.tr/bursayildirim-ilcesi-meb-okullari-uygulamasi.asp. 